\title{
Detection and Identification of Multiple Mycobacterial Pathogens by DNA Amplification in a Single Tube
}

\author{
Steve Wilton 1,3 and Debby Cousins 2 \\ ${ }^{1}$ Biotech International Ltd., Bentley, Western Australia, $6102 ;{ }^{2}$ Animal Health \\ Laboratories, Department of Agriculture, South Perth, Western Australia, 6151
}

A comparison of the DNA sequence of the 165 rRNA revealed a region in which there was a minor variation between the species of mycobacteria. This information was used to develop a multiplex amplification system that could identify the genus Mycobocterium and then distinguish between $M$. avium and $M$. intracellulare, two commonly encountered mycobacteria other than tuberculosis. The combination of these rRNA gene primers together with primers almed at the MPB70 gene of $M$. tuberculosis complex organisms permits the detection and identification of clinically significant mycobacteria in a single tube. An amplification product of $1030 \mathrm{bp}$ is indicative of the genus Mycobacterium and smaller fragments of 850,372 , and 180 bp are the positive signals for $M$. intracellulare, $M$. tuberculosis complex, and $M$. avium, respectively.

\footnotetext{
${ }^{3}$ Present Address: Australian Neuromuscular Research Institute, QE II Medical Centre, Nedlands, Western Australia, 6009.
}

$\mathbf{T}$ he genus Mycobacterium contains a number of common and serious pathogens to both man and animals. Man is the natural reservoir for $M$. tuberculosis and it is this organism and others of the $M$. tuberculosis complex that are responsible for 20 million active infections per year which lead to 5000 deaths per day. ${ }^{(1)}$ Although these figures are geographically biased toward densely populated and less developed regions, tuberculosis is considered a "controlled disease" only in more advanced countries. In addition to the problems associated with the $M$. tuberculosis complex, other species of mycobacteria are opportunistic pathogens and can pose a serious threat to any immunocompromised individual (age, secondary infections, immunosuppressive therapy, etc). The $M$. tuberculosis complex (which includes $M$. tuberculosis, $M$. bovis BCG, and $M$. bovis) and the opportunistic pathogens $M$. avium and $M$. intracellulare are the most common pathogenic Mycobacterium species isolated from clinical specimens. At the Mycobacterium Reference Laboratory in Western Australia between July, 1990, and June, 1991, these species accounted for $87.05 \%$ of all Mycobacterium species identified.

There are two approaches commonly used in the diagnosis of mycobacterial infections. Microscopy is used as a rapid method to detect acid-fast bacteria directly in smears, but it lacks sensitivity because it will only detect greater than 10,000 organisms $/ \mathrm{ml}^{(2)}$ and does not permit identification of the species involved. The culture of samples for mycobacteria allows for subsequent identification of species from positive specimens, but the slow growth of many pathogenic mycobacteria may result in a delay of 2-8 weeks before the organism is isolated by conventional culture methods, and a further 2-4 weeks before an identification is made using conventional biochemical and drug sensitivity tests. ${ }^{(3)}$ Isolates are normally considered to belong to the Mycobacterium genus by their ability to withstand decontamination with strong acid or alkali, their characteristic growth morphology, and their ability to remain acid fast when stained with the Ziehl-Neelsen stain.

The use of DNA probes has been reported for the rapid identification of the $M$. tuberculosis and $M$. aviumintracellulure complex, but the use of these probes is expensive and only one species can be screened in each test. The development of the BACTEC system, a radiometric method used for detecting mycobacteria in clinical specimens by monitoring carbon dioxide released from a broth medium containing a radioactively labeled substrate, has reduced the time taken for detection of M. tuberculosis. When used in combination with the BACTEC system, DNA probes have considerably decreased the time required for diagnosis, with reports that up to $83 \%$ of $M$. tuberculosis specimens can be detected within 18 days. ${ }^{(4-6)}$ Polymerase chain reaction (PCR) or DNA amplification has been used by many for the rapid detection of fastidious or slowgrowing pathogens in recent times. $(7-10)$

We recently reported the applica- 
tion of DNA amplification to the detection and identification of $M$. bovis, ${ }^{(11)}$ the causative organism of bovine tuberculosis and a member of the $M$. tuberculosis complex. This paper describes an extension of this test in the development of a multiplex PCR which, by utilizing primers to the $16 \mathrm{~S}$ rRNA gene, detected all members of the genus Mycobacterium tested and distinguished the $M$. tuberculosis complex organisms from the commonly encountered opportunistic pathogens, $M$. avium and $M$. intracellulare.

\section{MATERIALS AND METHODS}

\section{Bacterial strains}

Reference strains of $M$. tuberculosis and 25 other mycobacteria were obtained from the Mycobacterium Reference Laboratory (Perth, Western Australia). The reference strain of $M$. bovis was obtained courtesy of CSIRO (Melbourne). The stains used were $M$. aurum (ATCC 23366), M. avium (TMC 715), M. bovis (AN5), $M$. chelonae subsp. absceccus (ATCC 19977), M. chitae (ATCC 19627), M. duvalii (NCTC 358), $M$. flavescens (ATCC 14474), M. fortuitum (NCTC 3631), $M$. gadium (ATCC 27726), M. gastri (ATCC 15754), M. gilvum (NCTC 10742), M. gordonae (ATCC 14470), M. intracellulare (ATCC 13950), M. kansasii (ATCC 12478), M. marinum (ATCC 927), $M$. nonchromogenicum (ATCC 19530), $M$. neoaurum (ATCC 25795), $M$. parafortuitum (ATCC 19686), M. phlei (ATCC 11758), M. scrofulaceum (ATCC 19981), $M$. terrae (ATCC 15755), M. thermoresistable (ATCC 19527), $M$. triviale (ATCC 23292), M. tuberculosis H37Rv (NCTC 7416), M. ulcerans (ATCC 19423), M. vaccae (ATCC 15483), and $M$. xenopi (NCTC 10042).

A number of other bacterial strains, closely related to mycobacteria or commonly isolated in routine bacteriology laboratories, were tested. These strains were from the Department of Agriculture culture collection or obtained from Royal Perth Hospital (Perth, Western Australia). The bacteria tested included Rhodacoccus equi, Nocardia asteroides, $N$. braziliensis, Actinomyces bovis, Escherichia coli, Klebsiella pneumonia, Staphylococcus aureus, Streptococcus pneumonia, Pseudomonas aeruginosa, Serratia liquefaciens, Aeromonas hydrophila, Actinomyces pyogenes, Haemophilus in- fluenzae, Salmonella tryphimurium, and Proteus mirabilus.

\section{Sample Preparation}

All mycobacterial strains were grown as described by using standard methods on egg-based medium. ${ }^{(3)}$ Other bacterial strains were grown using standard bacteriological procedures.

Colony growth from each strain was mixed in $0.5 \mathrm{ml}$ of sterile water in a bijou bottle containing five sterile glass beads until a suspension equivalent to a No. 5 MacFarland Opacity standard (Difco) was obtained. A 10fold dilution in sterile water was heated to $94^{\circ} \mathrm{C}$ for $10 \mathrm{~min}$ and the samples were stored frozen at $-20^{\circ} \mathrm{C}$ until tested.

\section{Oligonucleotide Primers}

Oligonucleotide primers were synthesized on a Pharmacia Gene Assembler Plus and gel-purified on a $20 \%$ polyacrylamide gel containing $7 \mathrm{M}$ urea. The oligonucleotides were visualized by UV imaging ${ }^{(12}$ ) and desalted on NAP-10 columns (Pharmacia). The design of the multiplex reaction utilizing the $16 \mathrm{~S}$ rRNA sequence information is shown in Figure 1a. The nucleotide sequence, the concentration at which the primers were used, and the expected product sizes from the amplification reactions are shown in Table 1.

\section{Amplification Conditions}

Reactions were carried out in $25 \mu$ l containing $5 \mu \mathrm{l}$ of the $5 x$ reaction mix (335 mM Tris- $\mathrm{HCl}, \mathrm{pH} \mathrm{8.8,} \mathrm{at} 25^{\circ} \mathrm{C}, 83$
$\mathrm{mM}\left(\mathrm{NH}_{4}\right)_{2} \mathrm{SO}_{4}, 1 \mathrm{mM}$ dNTP, $2.25 \%$ Triton $\mathrm{X}-100$, and $1 \mathrm{mg} / \mathrm{ml}$ gelatin), 2 $\mathrm{mM} \mathrm{MgCl}_{2}$, oligonucleotides as specified in Table 1, 0.5 units of Taq DNA polymerase (Biotech International Ltd.), water to $20 \mu \mathrm{l}$, and $5 \mu \mathrm{l}$ of the sample. In all cases, the test sample contained bacteria at a concentration of about $5-20$ cells/ $\mu$ l. The reaction mixes were covered with $30 \mu$ l of paraffin oil to prevent evaporation during amplification in a Corbett FTS-1 thermal cycler (Bioquest Ltd). The amplification was performed by cycling the samples through $94^{\circ} \mathrm{C}$ (denaturation), $62^{\circ} \mathrm{C}$ (annealing), and $75^{\circ} \mathrm{C}$ (extension). The reactions were held at the denaturation temperature for $5 \mathrm{~min}$ for the first cycle and $30 \mathrm{sec}$ for the subsequent 39 cycles. Annealing and extension temperatures were both maintained at $3 \mathrm{~min}$ each throughout the amplification. Upon completion of the reaction, a 5- $\mu$ l aliquot was removed, mixed with an equal volume of $2 x$ loading buffer, and subjected to electrophoresis at $100 \mathrm{~V}$ for $2 \mathrm{hr}$ on a $3 \%$ agarose gel in Tris-acetate buffer (40 mM Tris-acetate, $1 \mathrm{~mm}$ EDTA). The bands were visualized and photographed on a medium wavelength UV transilluminator after staining with ethidium bromide.

\section{RESULTS AND DISCUSSION}

The 16S rRNA gene of mycobacteria has been characterized extensively and a set of primers specific for the genus Mycobacterium has been described.(13) This genus-specific region includes a

\section{S rRNA Gene}

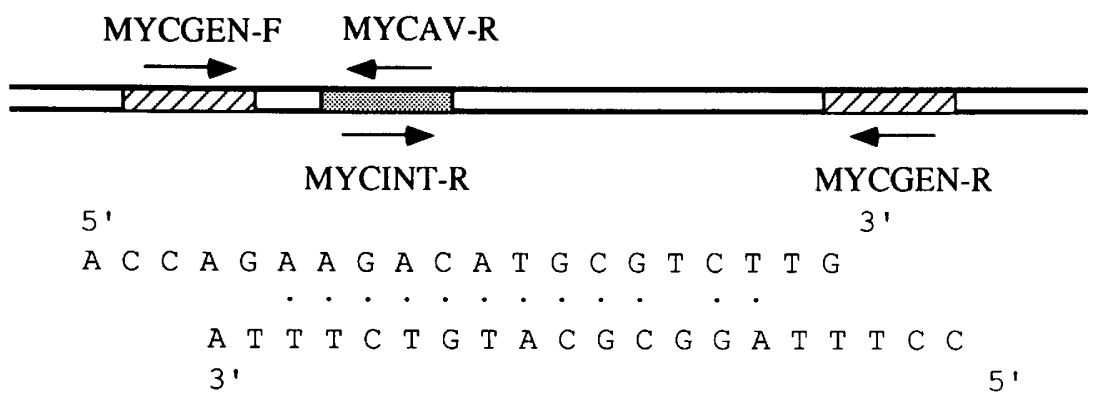

FIGURE 1 (Top) Annealing sites of the genus-specific and species-specific primers (as described in Table 1) to the 16S rRNA of Mycobacteria. The TB1 primers have not been shown because these anneal elsewhere in the mycobacterial genome. (Hatched area) Conserved DNA sequence for mycobacterial rRNA genes; (shaded area) DNA sequence variation between different mycobacterial species. (Bottom) Diagram of how MYCAV-R binds to MYCINT-F. 
TABLE 1 Nucleotide Sequence and Expected Product Size of Primer Pairs Used in the Multiplex reaction

\begin{tabular}{llcc}
\hline Primer & Sequence $\left(5^{\prime} \rightarrow 3^{\prime}\right)$ & $\begin{array}{r}\text { Concentration } \\
(\mathrm{nM})\end{array}$ & $\begin{array}{c}\text { Product size } \\
(\mathrm{bp})\end{array}$ \\
\hline MYCGEN-F & AGAGTTTGATCCTGGCTCAG & 250 & $1030^{\mathrm{a}}$ \\
MYCGEN-R & TGCACACAGGCCACAAGGGA & 250 & \\
MYCAV-R & ACCAGAAGACATGCGTCTTG & 70 & $180^{\mathrm{b}}$ \\
MYCINT-F & CCTTTAGGCGCATGTCTTTA & 350 & $\mathbf{8 5 0}^{\mathrm{c}}$ \\
TB1-F & GAACAATCCGGAGTTGACAA & 200 & $372^{\mathrm{d}}$ \\
TB1-R & AGCACGCTGTCAATCATGTA & 200 & \\
\hline
\end{tabular}

${ }^{a}$ MYCGEN-F and MYCGEN-R generate a 1030-bp product.

${ }^{\mathrm{b}}$ MYCAV-R and MYCGEN-F generate a 180 -bp product.

${ }^{C}$ MYCINT-F and MYCGEN-R generate a 850-bp product.

${ }^{\mathrm{d}} \mathrm{TB} 1-\mathrm{F}$ and TB1-R generate a 372-bp product. sequence where there was minor sequence variation between the species of mycobacteria. This information was used to develop a single-tube reaction that would be able to detect the genus tween the $M$. tuberculosis complex and two commonly encountered atypical mycobacteria, namely $M$. avium and $M$. intracellulare, on the basis of the size and combination of the amplification products.

Figure 2 shows the amplification products generated from various species of mycobacteria using the primers described in Table 1 . In all cases where mycobacteria were added to the reaction, a 1030 -bp product was generated from the genus-specific primers. These oligonucleotides, MYCGEN-F and MYCGEN-R, described previously, ${ }^{(13)}$ were found to be specific for the genus Mycobacterium and did not cross-react with other genera tested. The primers that were designed to differentiate $M$. avium from $M$. intracellulare generated the appropriatesized product only in the presence of their specific target, with the exception that the two strains of $M$. paratuberculosis tested, which generated the 180bp product typical for $M$. avium. This was not unexpected since $M$. paratuberculosis is very closely related to $M$. avium, and, at the DNA level in the region of the specific priming, had an identical sequence. It was envisaged that there may be some cross-reaction between the species-specific primers and other mycobacteria species because the DNA sequence variation in this particular region was not exMycobacterium and then distinguish be- tensive. It was of interest to note that there was no extensive primer-dimer formation, even though there was considerable complementation existing between the two species-specific primers (Fig. 1b). These primers anneal to the same region of the rRNA gene but in opposite directions. The high degree of specificity and lack of primer-dimer formation is thought to be due to the stringent annealing conditions, the two-base mismatch at the $3^{\prime}$ ends, and the low levels of Taq DNA polymerase used in the amplifications.

The reaction conditions were deliberately designed for a high degree of sensitivity and readily detected less than 100 cells. Previous experience has shown us that high numbers of cells in a test could sometimes lead to spurious results but this could easily be overcome by reducing the number of cycles or diluting the test specimen. It is generally easier to dilute the test sample prior to the amplification reaction rather than undertaking extensive procedures of cell concentration. Although initial tests were performed using 40 cycles, we found that equivalent results could be obtained after 35 cycles of amplification and hence all subsequent tests have been performed using this minimum number of cycles. We also found that a single colony was sufficient to perform the test. Five microliters of a suspension, $100 \mu \mathrm{l}$ of sterile water, and heated to $94^{\circ} \mathrm{C}$ for $10 \mathrm{~min}$, was sufficient to provide enough DNA to use reproducibly in the amplification reaction.

As expected, some amount of "fine tuning" was required to generate a balanced spread of bands. For example, higher amounts of either internal primer (MYCAV-R or MYCINT-F) resulted in the species-specific products swamping the reaction at the expense of the genus-specific signal. The annealing temperatures were kept high to minimize any potential cross-reaction with other species.

Perhaps one of the most surprising observations was the general inhibition of the reaction when greater than 1 unit of Taq DNA polymerase was used in the amplification. In these failed amplifications, large amounts of obtained by mixing a single colony in

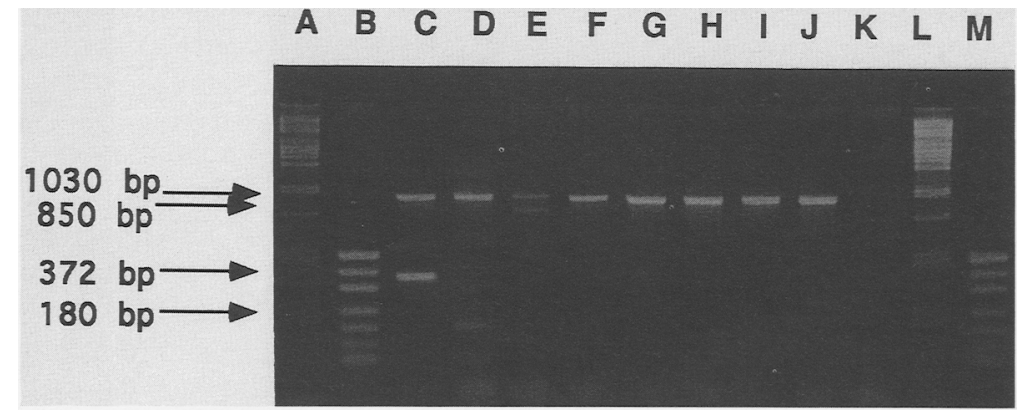

FIGURE 2 Multiplex amplification products from various Mycobacterium species after electrophoresis on a $3 \%$ agarose gel and staining with ethidium bromide. (Lanes $A$ and $L$ ) $\lambda$ PstI high-molecular-weight standard; (lanes $B$ and $M$ ) pUC19 Hpall low-molecular-weight standard; (lane $C$ ) $M$. bovis; (lane $D$ ) $M$. avium; (lane $E$ ) $M$. intracellulare; (lane $F$ ) $M$. scrofulaceum; (lane G) M. phlei; (lane $H$ ) $M$. chelonae; (lane I) M. fortuitum; (lane $D$ M. marinum; (lane $K$ ) $E$. coli. The genus-specific signal of $1030 \mathrm{bp}$ is common to all Mycobacterium species whereas only $M$. bovis, $M$. avium, and $M$. intracellulare targets generated the species-specific products of 372,180 , and $850 \mathrm{bp}$, respectively. 
primer-dimer were generated, suggesting that this may have swamped out the reaction. No other sources of enzyme were used in this study, and this phenomena may be specific to the Taq DNA polymerase produced by Biotech International.

Rapid detection and identification of mycobacterial pathogens is necessary for effective treatment. The DNA amplification method described in this paper allows for the detection of mycobacteria species and the concomittant identification of clinically significant pathogens such as the $M$. tuberculosis complex and the atypical mycobacteria, $M$. avium and $M$. intracellulare. The reaction is carried out in a single tube and a result can be obtained within a few hours of obtaining a suspect colony. This approach has many distinct advantages over the traditional methods of biochemical identification, including speed, simplicity, and convenience. The test can be applied to isolated colonies of suspect mycobacteria instead of using conventional biochemical and drug sensitivity tests, which can take between 2 and 4 weeks. Because of the test's exquisite sensitivity, we have found that a single colony is sufficient to perform the test and a result can be available within 4 hr. This test has advantages over DNA probe techniques in that it can be used to test for the three major pathogens of the Mycobacterium genus in a single tube, which is a saving to the laboratory in terms of time and money. It is also envisaged that this PCR could be used in conjunction with the BACTEC system for the rapid identification of these pathogens directly from BACTEC media, in a similar manner to which DNA probes are currently used. Again, because of the sensitivity of the PCR, this could reduce further the time taken for diagnosis of mycobacterial infections in specimens.

We previously reported the application of primers to the gene for the MPB70 secretory protein in detecting members of the $M$. tuberculosis complex. ${ }^{(11)}$ In more recent work, amplification reactions directly from treated clinical specimens gave good correlation with culture results, although a weak positive signal was occasionally observed in some specimens found to be negative for $M$. tuberculosis by culture. $^{(14)}$ There are several possibilities to account for these weak signals. In some cases, the amplification test may have detected cells of the $M$. tuberculosis complex that were no longer viable and hence missed by culture. The weak signals may be due to crossreaction with other species of mycobacteria or a mixed infection where low levels of $M$. tuberculosis were masked by the culture of other species of mycobacteria. The application of the multiplex PCR described in this paper to the direct detection of Mycobacterium species in these types of specimens may clarify the earlier results. The multiplex PCR described here is an improvement on methods described earlier, ${ }^{(11,14)}$ which only identified isolates if they were from the $M$. tuberculosis complex. This refined method not only provides a means of classifying isolates as belonging to the genus Mycobacterium and but can also identify members of the $M$. tuberculosis complex or the species M. avium or M. intracellulare in a single test. The genusspecific reaction is built into the amplification reaction because each of the external genus primers also serve as a primer for the $M$. avium or $M$. intracellulare reaction. As such, it is an builtin control in the system to assist in the accurate identification of Mycobacterium species. The successful application of this multiplex technique for direct detection in specimens would reduce the time for diagnosis of a large proportion of pathogenic mycobacterial diseases to within 2 or 3 days.

\section{ACKNOWLEDGMENTS}

Parts of this work were supported by Biotech International and the Australian Brucellosis and Tuberculosis Eradication Campaign. We acknowledge with thanks the assistance and support of the following people: Shelley Dorosz, Chris Fisher, Trevor Ellis, and Barry Francis. We also thank Beth Gow of the Mycobacteria Reference Laboratory and Claire Khinsoe of Royal Perth Hospital for supplying many of the bacterial strains used in this work.

\section{REFERENCES}

1. Dawson, D.J. 1990. Tuberculosis in Australia: An unfinished fight. Med. $J$. Aust. 154: 75-76.

2. Bates, J.H. 1979. Diagnosis of tuberculosis. Chest (suppl.) 76: 757-763.
3. Vestal, A.L. 1975. Procedures for the isolation and identification of mycobacteria. Training and Consultative Division Centre for Disease Control, Atlanta.

4. Peterson, E.M., R. Lu, C. Floyd, A. Nakasone, G. Friedly, and L.M. de la Maza. 1989. Direct dentification of Mycobacterium tuberculosis, Mycobacterium avium, and Mycobacterium intracellulare from amplified primary cultures in BACTEC media using DNA probes. J. Clin. Microbiol. 27: 15431547.

5. Body, B.A., N.G.Warren, A. Spicer, D. Henderson, and M. Chery. 1989. Use of Gen-Probe and Bactec for the rapid isolation and identification of Mycobacteria. Am. J. Clin. Pathol. 93: 415-420.

6. Ellner, P.D., T.E. Kiehn, R. Cammarata, and M. Hosmer. 1988. Rapid detection and identification of pathogenic Mycobacteria by combining radiometric and nucleic acid probe methods. J. Clin. Microbiol. 26: 1349-1352.

7. Olive, D.M. 1989. Detection of enterotoxigenic Escherichia coli after polymerase chain reaction amplification with a thermostable DNA polymerase. J. Clin. Microbiol. 27: 261265.

8. Ostergaard, L., S. Birkelund, and G. Christiansen. 1990. Use of polymerase chain reaction for the detection of Chlamydia trachomatis. 28: 1254-1260.

9. Malloy, D.C., R.K. Nauman, and H. Paxton. 1990. Detection of Borrelia burgdorfferi using the polymerase chain reaction. J. Clin. Microbiol. 28: 1089-1093.

10. Moser, D.R., L.V. Kirchhoff, and J.E. Donelson. 1989. Detection of Trypanosoma cruzi by DNA amplification using the polymerase chain reaction. J. Clin. Microbiol. 27: 1477-1482.

11. Cousins, D.V., S.D. Wilton, and B.R. Francis. 1991. Use of DNA amplification for the rapid identification of Mycobacterium bovis. Vet. Microbiol. 27: 187-195.

12. Clarke, P., H. Lin, and G. Wilcox. 1982. Ultraviolet imaging: A simple method for detecting nucleic acids in preparative gels. Anal. Biochem. 124: 88-91.

13. Boddinghaus, B., T. Rogall , T. Flohr, H. Blocker, and E.C. Bottger. 1990. Detection and identification of 
mycobacteria by amplification of rRNA. J. Clin. Microbiol. 28: 17511759.

14. Cousins, D.V., S.D. Wilton, B.R. Francis, and B.L. Gow. 1992. Use of PCR for the rapid diagnosis of tuberculosis. J. Clin. Microbiol. (in press).

Received November 25, 1992; accepted in revised form January 24, 1992. 


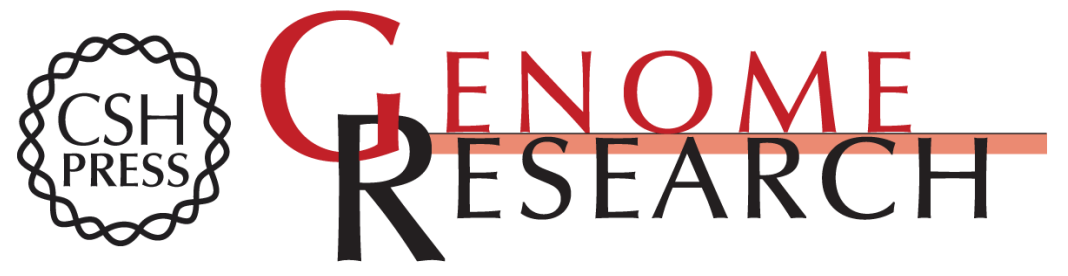

\section{Detection and identification of multiple mycobacterial pathogens by DNA amplification in a single tube.}

$S$ Wilton and D Cousins

Genome Res. 1992 1: 269-273

Access the most recent version at doi:10.1101/gr.1.4.269

References This article cites 11 articles, 6 of which can be accessed free at:

http://genome.cshlp.org/content/1/4/269.full.html\#ref-list-1

\section{License}

Email Alerting Receive free email alerts when new articles cite this article - sign up in the box at the Service top right corner of the article or click here.

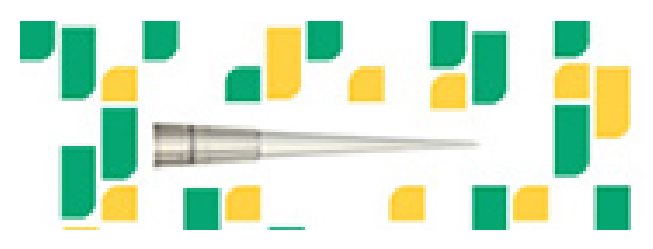

To subscribe to Genome Research go to: https://genome.cshlp.org/subscriptions 